\begin{tabular}{|c|l|}
\hline Title & Deposition transfection technology using a DNA complex with a thermoresponsive cationic star polymer \\
\hline Author(s) & $\begin{array}{l}\text { Zhou, Y ue Min; Ishikawa, Ayaka; Okahashi, Ryohei; Uchida, Kingo; Nemoto, Y asushi; Nakayama, Mitsuko; } \\
\text { Nakayama, Yasuhide }\end{array}$ \\
\hline Citation & $\begin{array}{l}\text { Journal of Controlled Release, 123(3), 239-246 } \\
\text { https://doi.org/10.1016/.jconrel.2007.08.026 }\end{array}$ \\
\hline Issue Date & 2007-01-20 \\
\hline Doc URL & http://hdl.handle.net/2115/32286 \\
\hline Type & article (author version) \\
\hline File Information & JOCR123 3.pdf \\
\hline
\end{tabular}

Instructions for use 


\section{Deposition Transfection Technology Using a DNA Complex with a Thermoresponsive Cationic Branched Polymer}

Running Head: Deposition transfection technology

Yue-Min Zhou ${ }^{1}$, Ryohei Okahashi ${ }^{1,3}$, Ayaka Ishikawa ${ }^{1}$, Kingo Uchida ${ }^{3}$

Yasushi Nemoto ${ }^{1,2,4}$, Mitsuko Nakayama ${ }^{1}$ and Yasuhide Nakayama ${ }^{1,2} *$

${ }^{1}$ Department of Bioengineering, Advanced Medical Engineering Center

National Cardiovascular Center Research Institute

${ }^{2}$ Division of Biotechnology and Macromolecular Chemistry, Faculty of Engineering, Hokkaido University

${ }^{3}$ Department of Materials Chemistry, Faculty of Science and Technology

Ryukoku University

${ }^{4}$ Development Department, Chemical Products Division, Bridgestone Co.

*To whom correspondence should be addressed:

Department of Bioengineering, Advanced Medical Engineering Center

National Cardiovascular Center Research Institute

5-7-1 Fujishiro-dai, Suita, Osaka 565-8565, Japan

Telephone: (+81) 6-6833-5012 (ex. 2624)

Fax: (+81) 6-6872-8090

E-mail: nakayama@ri.ncvc.go.jp 


\begin{abstract}
A novel non-viral gene transfection method in which DNA complexes were kept in contact with a deposition surface (deposition transfection) was developed. We designed a novel aqueous thermoresponsive adsorbent material for DNA deposition, which was a star-shaped copolymer with 4 branched chains. Each chain comprised a cationic poly( $N, N$-dimethylaminopropyl acrylamide) (PDMAPAAm) block (Mn: ca. 3,000 $\mathrm{g} \cdot \mathrm{mol}^{-1}$ ), which formed an inner domain for DNA binding and a thermoresponsive poly( $N$-isopropylacrylamide) (PNIPAM) block ( $M n$ : ca. 6,000 $\mathrm{g} \cdot \mathrm{mol}^{-1}$ ), which formed an outer domain for surface adsorption. Complex formation between the copolymer and the luciferase-encoding plasmid DNA occurred immediately upon simple mixing in an aqueous medium; polyplexes approximately $100 \mathrm{~nm}$ in size were formed. Because the lower critical solution temperature of the polyplexes was approximately $35^{\circ} \mathrm{C}$, they could deposit on the substrate by precipitation from an aqueous solution upon warming, which was confirmed by quartz crystal microbalance (QCM) method and water contact angle measurement. When COS-1 cells were cultured on the polyplex-deposited substrate in a culture medium, the luciferase activity observed was higher than that observed on a DNA-coated substrate with or without the cationic polymer before and after complete adhesion and by conventional solution transfection using the polyplexes. The activity was enhanced with an increase in the charge ratio (surfactant/pDNA) with permissible cellular cytotoxicity.
\end{abstract}

Keywords: DNA delivery, Reverse transfection, Deposition transfection, Thermoresponsive polymer, Cationic polymer 


\section{Introduction}

There are several issues to be resolved regarding clinical applications that use virus vectors for gene therapy, such as the antigenicity and toxicity of the virus or the possibility of disease transfection. On the other hand, cationic polymers such as polyethylenimine (PEI) [1,2] and dimethylamino group-containing polymers [3-6], which can generate nanoparticles by the formation of polyion complexes, i.e., "polyplexes," with a plasmid DNA, have a high potential to be one of the major carriers in non-viral gene delivery systems due to the many advantages they offer over viral systems. However, several research trials using non-viral carriers have not always achieved the expected results in terms of transfection efficiency; this is because the gene expression level is not as high as that obtained with viral carriers [7,8]. Therefore, an efficient technology and methodology of gene transfection based on the designed carrier materials without the use of virus vectors need to be developed.

The conventional procedure of gene transfection involves complexing the non-viral carrier with a plasmid DNA and then adding it to a cell culture medium. In this case, preincubation of the target cells is necessary for at least 1 day before transfection. In addition, generally, serum cannot be used as the transfection medium because the DNA-carrier complex often interacts with serum components, leading to suppressed gene transfection ability. Therefore, a reverse transfection method was developed as another practical approach for gene transfection [9-11]. This method is performed by culturing cells on a plasmid DNA-loaded substrate. DNA-loaded substrates are generally prepared by mixing DNA with cationic polymers that have been physically adsorbed or chemically bonded to the substrate. The cells were in direct contact with the DNA-loaded surface during the culture period; this differs from conventional transfection culture in which the contact time is limited. In addition, transfectional microarrays that permit parallel transfer of multiple genes into cultured 
cells were developed for high-throughput reverse genetics research because the reverse transfection method can be performed with spatial and temporal control $[10,11]$. However, it cannot be said that the transfection efficiency of this method is as satisfactory as that of the conventional transfection method. Therefore, an additional physical stimulus, such as an electric pulse, was used to enhance the transfection efficiency [12,13].

Recently, in order to improve the gene transfection efficiency of methods that use cationic polymers as gene carriers, we designed a series of branched cationic polymers [3]. The series comprised linear and 3-, 4-, or 6-branched PDMAPAAm polymers that functioned as novel high-performance gene carriers termed the star vector. They were prepared by iniferter (initiator-transfer agent-terminator)-based photo-living radical polymerization $[14,15]$ from their respective multidithiocarbamate-derivatized benzenes (multifunctional iniferters) and by using DMAPAAm as a cationic monomer. These experiments revealed that the transfection efficiency increased with the degree or chain length of branching [3], or by blocking with a nonionic chain [16].

As a continuation of our study on the star vector, in this study, we designed a novel adhesive transfection material to improve the reverse transfection method. The material had 4-cationic PDMAPAAm branching for binding with a plasmid DNA to form polyplexes and was blocked with poly( $N$-isopropylacrylamide) (PNIPAM) chains for surface deposition on a hydrophobic substrate. PNIPAM is one of the most well-known thermoresponsive polymers that precipitates in water at above $32^{\circ} \mathrm{C}$ but is water soluble at room temperature [17]. Due to this unique feature, PNIPAM has been utilized for thermoresponsive tissue culture dishes [18,19], in drug delivery vehicles [20,21], for hemostasis [22,23], and in 3D extracellular matrix materials [24]. The PNIPAM-blocked complex of the star vector and a plasmid DNA was adsorbed onto a culture substrate, and cells were then cultured on the complex-deposited substrate. The transfection efficiency of the newly developed transfection method (deposition 
transfection), which is an improved reverse transfection method, was evaluated by comparing it with that of the conventional transfection method. Further, the cytotoxicity was evaluated after deposition transfection using COS-1 cells.

\section{Materials and Methods}

\subsection{Materials}

1,2,4,5-Tetrakis(bromomethyl)benzene was obtained from Sigma-Aldrich (Milwaukee, WI). Sodium $N, N$-diethyldithiocarbamate, $N, N$-dimethylacrylamide (DMAAm), and $N$-isopropylacrylamide (NIPAM) were purchased from Wako Pure Chemical Ind., Ltd. (Osaka, Japan). The other chemical reagents were commercially obtained from Wako Pure Chemical Ind., Ltd. The DMAAm was distilled under reduced pressure, and the NIPAM was recrystallized with methanol/hexane prior to use in order to remove the stabilizer. The other reagents were purified before use according to requirements.

\subsection{General Methods}

${ }^{1} \mathrm{H}$-nuclear magnetic resonance (NMR) spectra were recorded in deuterium oxide $\left(\mathrm{D}_{2} \mathrm{O}\right)$ with a $300 \mathrm{MHz}$ NMR spectrometer (Gemini-300; Varian, Palo Alto, CA) at room temperature. Gel permeation chromatography (GPC) analyses using $\mathrm{N}, \mathrm{N}$-dimethylformamide as a solvent were performed with an HPLC-8020 instrument (Tosoh, Tokyo, Japan) using Tosoh TSKgel $\alpha-3000$ and $\alpha-5000$ columns. The columns were calibrated with narrow weight distribution polyethylene glycol standards (Tosoh).

2.3. Synthesis of PDMAPAAm 4-Branched Polymer and PDMAPAAm-PNIPAM 4-Branched Block Copolymer 
The PDMAPAAm-PNIPAM 4-branched block copolymer, 1,2,4,5-tetrakis( $N, N$-diethyldithiocarbamyl(poly( $N, N$-dimethylacrylamide))-block-poly( $\mathrm{N}$-isopropylacrylamide))benzene was synthesized using the sequential steps of iniferter-based living radical photopolymerization [3,25,26] with 1,2,4,5-tetrakis( $N, N$-diethyldithiocarbamylmethyl)benzene as the multifunctional iniferter and DMAPAAm and NIPAM as the cationic and thermoresponsive monomers, respectively. The synthesis procedure is described below.

DMAPAAm (0.86 g, $5.5 \mathrm{mmol})$ was added to $6 \mathrm{ml}$ benzene solution containing the multifunctional iniferter (72 mg, $0.1 \mathrm{mmol}$ ); this was diluted to a final volume of 20 $\mathrm{ml}$ with methanol and placed into a 50-mL quartz crystal tube. After bubbling with dry $\mathrm{N}_{2}$ gas for 5 min to exclude air, the solution was irradiated for 90 min with a 200-W high-pressure mercury lamp (SPOT CURE; USHIO, Tokyo, Japan) under an $\mathrm{N}_{2}$ atmosphere at room temperature. The light intensity was set to $1 \mathrm{~mW} / \mathrm{cm}^{2}$ at a wavelength of $250 \mathrm{~nm}$ (UVR-1; TOPCON, Tokyo, Japan). The reaction mixture was concentrated and adjusted to an appropriate concentration in order to facilitate purification by precipitation in a large volume of ether. Reprecipitation was carried out in a methanol-ether system. The final precipitate was dried under vacuum to yield a PDMAPAAm 4-branched polymer (conversion, 13\%). The molecular weight $(\mathrm{Mn})$ as determined by GPC analysis was 3,700 $\mathrm{g} \cdot \mathrm{mol}^{-1}$. ${ }^{1} \mathrm{H}-\mathrm{NMR}$ : $\delta$ 1.7-1.5 (br, 3H,

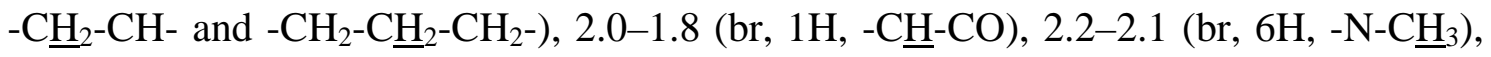
2.4-2.2 (br, 2H, - $\left.\underline{\mathrm{C}}_{2}-\mathrm{N}\left(\mathrm{CH}_{3}\right)_{2}\right)$, 3.2-3.0 (br, 2H, -NH- $\underline{\mathrm{H}}_{2}-$ ), 7.8-7.4 (br, $\left.1 \mathrm{H},-\mathrm{NH}\right)$.

A methanol solution (20 mL) of the obtained PDMAPAAm 4-branched polymer (650 mg, $0.18 \mathrm{mmol})$ and NIPAM (1.24 g, $11 \mathrm{mmol}$ ) was placed into a 50-ml quartz crystal tube and deoxygenated by bubbling with dry $\mathrm{N}_{2}$ gas for $5 \mathrm{~min}$. The solution was then irradiated for 90 min under the abovementioned conditions. The reaction mixture was concentrated and precipitated in $400 \mathrm{ml}$ ether. Reprecipitation was carried out in a methanol-ether system. The final precipitate was dried under vacuum 
to yield the PDMAPAAm-PDMAAm 4-branched block copolymer (conversion, 19\%). The $M n$ as determined by GPC analysis was 9,300 $\mathrm{g} \cdot \mathrm{mol}^{-1}$. ${ }^{1} \mathrm{H}-\mathrm{NMR}: \delta 1.1-1.2$ (br, - $\mathrm{CH}\left(\mathrm{CH}_{3}\right)_{2}$ of NIPAM), 1.5-1.8 (br, $-\underline{\mathrm{C}}_{2} \mathrm{CH}-$ and $-\mathrm{CH}_{2} \underline{\mathrm{C}}_{2} \mathrm{CH}_{2}$ of PDMAPAAm), 2.2 (br, -N( $\left.\underline{\mathrm{C}}_{3}\right)_{2}$ of PDMAPAAm), 2.3-2.4 (br, $-\underline{\mathrm{C}}_{2} \mathrm{~N}\left(\mathrm{CH}_{3}\right)_{2}$ of DMAPAAm), 3.1-3.4 (br, -NHC $\underline{H}_{2}$ of PDMAAm), 4.0 (br, - $\mathrm{NHC}_{2}\left(\mathrm{CH}_{3}\right)_{2}$ of NIPAM).

\subsection{Preparation of DNA Complexes}

The PDMAPAAm-PNIPAM 4-branched block copolymer was dissolved in a saline solution. Aliquots of these solutions $(60 \mu \mathrm{l})$ were added to the luciferase-encoding plasmid DNA (pGL3-control) dissolved in $90 \mu$ l Tris-HCl buffer $(\mathrm{pH}$ 7.4) to obtain polymer/DNA ratios of from 1 to 15 , which correspond to cation/anion (C/A) ratios. The solutions (total volume, $150 \mu \mathrm{l}$; plasmid concentration, $20 \mu \mathrm{g} / \mathrm{ml}$ ) were mixed using a pipette to generate DNA complexes.

The mean diameters and polydispersity of the DNA complexes in a saline solution of the same concentration as that used for transfection at a C/A ratio of 5 were determined by employing dynamic light scattering (DLS) on an ELS-8000 system (Otsuka Co., Osaka, Japan) equipped with a 10-mW He-Ne laser. The data are presented as means \pm S.D. $(n=5)$.

\subsection{Surface Characterization}

The surface wettability was evaluated by measuring the static contact angles toward pure water using the sessile drop method with a contact angle meter (CA-V 200; Kyowa Kaimenkagaku Co., Ltd., Tokyo, Japan).

The deposition of the DNA complexes was measured using a quartz crystal microbalance (QCM) system (QCM922, Seiko EG\&G Co., Osaka, Japan). A 9 MHz AT-cut quartz crystal disk vacuum-plated with gold electrodes $\left(0.198 \mathrm{~cm}^{2}\right)$ on each side was used as the piezoelectric quartz oscillator. One side of the electrodes was 
precoated with polystyrene (around $1 \mu \mathrm{m}$ thick) by casting in toluene solution.

\subsection{In vitro Transfection and Cell Viability Assays}

In vitro transfection was performed by the deposition transfection method as follows. An aqueous solution of the DNA complexes (25 $\mu \mathrm{l}$; plasmid concentration, $20 \mu \mathrm{g} / \mathrm{ml}$ ) was diluted with $70 \mu \mathrm{l}$ saline and then added into each well of 24-multiwell dishes (the amount of DNA added to the well, $0.5 \mu \mathrm{g} /$ well). After incubation at $37^{\circ} \mathrm{C}$ for 30 min, COS-1 cells (approximately $6 \times 10^{4}$ cells per well) in $1 \mathrm{ml}$ of Dulbecco's modified Eagle’s medium (DMEM) (Gibco, Invitrogen Corp., Carlsbad, CA) containing 10\% fetal bovine serum (FBS) (Hyclone Laboratories Inc., Logan, UT), penicillin (200 units/ml; ICN Biomedicals Inc., Aurora, OH), and streptomycin (200 mg/ml; ICN) were seeded and cultured in an atmosphere of $5 \% \mathrm{CO}_{2}$ at $37^{\circ} \mathrm{C}$ for $48 \mathrm{~h}$. The medium was removed, and the cells were washed twice with phosphate buffered saline (PBS) (-). The cells were lysed with $0.2 \mathrm{ml}$ of cell lysis buffer (Promega, Madison, WI) and mixed by vortexing. The lysate was centrifuged at $15,000 \mathrm{rpm}$ for $1 \mathrm{~min}$ at $4^{\circ} \mathrm{C}$, and $5 \mu \mathrm{l}$ of the supernatant was analyzed for luciferase activity using the Luminous CT-9000D (Dia-Iatron, Tokyo, Japan) luminometer. Relative light unit/s (RLU) were converted into the amount of luciferase (pg) using a luciferase standard curve, which was obtained by diluting recombinant luciferase (Promega) in lysis buffer. The protein concentrations of the cell lysates were measured by performing a Bio-Rad protein assay (BIO-RAD, Hercules, CA) using bovine serum albumin as the standard. The expressed luciferase represented the amount (mole quantity) standardized for the total protein content of the cell lysate. The data are presented as means \pm S.D. $(n=5)$.

In vitro transfection by conventional solution transfection was performed as follows. COS-1 cells (approximately $6 \times 10^{4}$ cells per well) were seeded prior to treatment in 24-well dishes and grown for $24 \mathrm{~h}$ in DMEM containing 10\% fetal calf serum in an atmosphere of $5 \% \mathrm{CO}_{2}$ at $37^{\circ} \mathrm{C}$. After 10 min of complex formation, 
transfection was performed by adding $25 \mu \mathrm{l}$ of the complex solutions into each well of the 24-well dishes with $0.5 \mathrm{ml}$ of OPTI-MEM I (Gibco, the amount of DNA added to a well, $0.5 \mu \mathrm{g} /$ well). After $4 \mathrm{~h}$ of incubation, the cells were washed once with PBS(-) and cultured in $1 \mathrm{ml}$ of DMEM containing 10\% FBS for an additional $48 \mathrm{~h}$. The medium was removed, and the cells were washed twice with PBS(-). Luciferase activity was measured similar to as described above.

Cytotoxicity was assessed by performing a cell viability assay using the water-soluble tetrazolium-8 (WST-8) method (Dojindo, Kumamoto, Japan). COS-1 cells were seeded $24 \mathrm{~h}$ prior to treatment in 96-well plates at 5,000 cells per well. The cells were treated under the same conditions used for the luciferase assay with $6.2 \mu \mathrm{l}$ of the transfection mixture; $0.124 \mu$ of pDNA was added to each well. The cells were treated under appropriate conditions for 3 h, washed once with PBS, and cultured in 50 $\mu \mathrm{l}$ of DMEM containing 10\% fetal calf serum for an additional $24 \mathrm{~h}$. To each well, 10 $\mu \mathrm{l}$ of WST-8 reagent $(5 \mathrm{mmol} / \mathrm{l})$ was added. After $2 \mathrm{~h}$ of incubation at $37^{\circ} \mathrm{C}$, absorbance at $450 \mathrm{~nm}$ was measured using a BIO-RAD microplate reader (Model 680). The data are presented as means \pm S.D. $(n=5)$.

\section{Results}

\subsection{Synthesis of PDMAPAAm-PNIPAM 4-Branched Block Copolymers.}

The PDMAPAAm-PNIPAM 4-branched block copolymer, which was designed as a thermoresponsive adsorbent material for the surface deposition of DNA, was synthesized by the sequential steps of iniferter-based living radical photopolymerization as depicted in the reaction scheme shown in Figure $1[3,25,26]$. As the first step, a PDMAPAAm cationic polymer with 4 branches with an $M n$ of approximately $3,700 \mathrm{~g} \cdot \mathrm{mol}^{-1}$ was obtained when a methanol solution of DMAPAAm was irradiated with UV for $90 \mathrm{~min}$ in the presence of the multifunctional iniferter. In 
the second step, the thermoresponsive monomer NIPAM from the obtained PDMAPAAm 4-branched polymers was photopolymerized under similar polymerization conditions. Upon UV irradiation in the presence of NIPAM, the $M n$ increased to approximately $9,300 \mathrm{~g} \cdot \mathrm{mol}^{-1}$ with a minimal increase in the polydispersity from 1.3 to 1.4. The GPC curve was completely shifted toward a high-molecular weight region after second polymerization as shown in our recent report [27]. The ${ }^{1} \mathrm{H}-\mathrm{NMR}$ spectra revealed that the peaks of the methyl protons at 1.1-1.2 ppm and those of $\mathrm{N}$-methylene protons at approximately $4.0 \mathrm{ppm}$, all of which originated from the NIPAM unit, were newly detected in the obtained polymers. Therefore, it can be inferred that graft copolymerization occurred at the terminals of each chain of the PDMAPAAm polymers to produce a block copolymer with 4 PDMAPAAm-PNIPAM block chains, comprising PDMAPAAm and PNIPAM blocks of approximately 750 and $1,500 \mathrm{~g} \cdot \mathrm{mol}^{-1}$, respectively.

\subsection{Preparation and Characterization of DNA Complexes}

The resultant PDMAPAAm-PNIPAM 4-branched block copolymer was a white solid that dissolved readily in water at room temperature. When an aqueous solution of the block copolymer was mixed with an aqueous solution of the luciferase-encoding plasmid DNA (pGL3), an increase in the DLS intensity was immediately observed, indicating the formation of polymer/DNA complexes. The mean cumulant diameter of the DNA complexes obtained from $150 \mu \mathrm{l}$ of an aqueous solution containing $21.6 \mu \mathrm{g}$ of the block copolymer and $3 \mu \mathrm{g}$ of DNA, whose mixing ratio was the same under the charge ratio of 5, was approximately $120 \mathrm{~nm}$ with extremely narrow polydispersity range of 0.129 (Figure 2). The DNA complex solution was precipitated in the physiological temperature range (Figure 3). The equilibrium transmittance and lower critical solution temperature (LCST) were approximately $55 \%$ and $36^{\circ} \mathrm{C}$, respectively. The particle size of the DNA complex as 
precipitated at $37^{\circ} \mathrm{C}$ was approximately $1,000 \mathrm{~nm}$ in mean cumulant diameter (polydispersity, 0.348), which was notably different from the value (approximately 100 $\mathrm{nm}$ ) obtained for those precipitated from an aqueous solution containing only the block copolymer (Figure 2). Therefore, upon heating to $37^{\circ} \mathrm{C}$, the DNA complexes could be precipitated for DNA deposition.

The deposition of the DNA complexes was directly measured from weight increase by using CQM apparatus. Little weigh change in the QCM measurement was observed even upon placing an aqueous solution (5 $\mu \mathrm{l})$ containing the DNA complexes obtained from $720 \mathrm{ng}$ of the block copolymer and $100 \mathrm{ng}$ of DNA on the polystyrene-coated electrode at room temperature. On the other hand, when the temperature was increased to $37^{\circ} \mathrm{C}$ the weight on the electrode was spontaneously increased to about $200 \mathrm{ng}$. This indicated that about one fourth of the DNA complexes applied was deposited on the QCM surface by warming.

In addition, the contact angle measurements showed that upon deposition and then air-drying of the DNA complexes obtained from $150 \mu \mathrm{l}$ of an aqueous solution containing $21.6 \mu \mathrm{g}$ of the block copolymer and $3 \mu \mathrm{g}$ of DNA, the receding water contact angle on the surface of a poly(ethylene terephthalate) (PET) used as a substrate extremely decreased from approximately $45^{\circ}$ to less than $10^{\circ}$. The PET surface became highly wettable after deposition of the DNA complexes. The high wettability remained almost unchanged after incubation with water at $37^{\circ} \mathrm{C}$ for 1 week, indicating highly durability in the deposition.

\subsection{In Vitro Transfection Efficiency and Cell Viability}

The transfection efficiency of the deposition transfection method with the luciferase-encoding plasmid pGL3 and the 2 types of cationic polymers-PDMAPAAm 4-branched polymer and PDMAPAAm-PNIPAM 4-branched block copolymer-was tested by changing the charge ratio from 1 to 15 using the model cell line COS-1 of 
monkey kidney cells and comparing these results with those of the conventional solution transfection method. In the absence of any polymer, negligible luciferase expression was exhibited, whereas weak expression was observed in the deposition transfection method by using cationic homopolymers (Figure 4A). There was little change in the expression level even upon increasing the charge ratio. On the other hand, high expression was observed by the deposition transfection method using block copolymer even in the presence of serum (Figure 4D); this expression was several times higher than that observed in the conventional method (Figure 4B). The highest expression $(\mathrm{C} / \mathrm{A}=15)$ in the deposition method was almost same value of PEI in the optimal conventional method in the absence of serum (Figure 4B), whereas the expression of PEI was extremely low in the deposition method because the polyplex with PEI could not deposit (Figure 4D). In both methods, the expression level increased with the charge ratio. Interestingly, the expression level in the reverse transfection method, in which the DNA complexes with the PDMAPAAm-PNIPAM copolymer were coated on the substrate by drying, was almost one-tenth of that observed in the deposition transfection method in which DNA complexes were adsorbed (Figure 4C).

Figure 5 illustrates the cell viability of the COS-1 cells transfected with the block copolymer using the deposition transfection method. Cell viability decreased significantly with the charge ratio. However, even at extremely high charge ratios exceeding 20, almost $60 \%$ of the viability, which was almost same value in PEI at charge ratio of 6 , was maintained.

\section{Discussion}

In the present study, we designed a unique gene adsorbent material possessing thermoresponsive properties in order to improve the reverse transfection method $[10,11]$. In ordinary reverse transfection, it is necessary to coat pDNA on the culture substrate 
with cationic matrix materials to ensure that the pDNA is firmly impregnated in the matrix adhered or bonded to the substrate. On the other hand, in our method, the pDNA was precipitated onto a culture substrate using a thermoresponsive polymeric adsorbent material immediately before the cells were seeded. Transfection experiments were performed without preculturing of cells or precoating of genes at least 1 day in advance, these steps are required in the conventional transfection and reverse transfection methods, respectively. In addition, culture medium with serum could be used as the transfection medium. Therefore, this novel transfection method, which is a modified reverse transfection method, is termed the deposition transfection method. The handling in the deposition method was illustrated in Figure 6.

The adsorbent material, which was the key strategy used in order to execute the deposition transfection method, comprised 4 AB-type blocked branches, each incorporating the following 2 different chemical entities: a cationic polymer block forming an inner domain and a thermoresponsive polymer block forming an outer domain. Multi-branching of the material was designed for effective adsorption. The branching number was easily controlled by changing the number of dithiocarbamate groups derivatized in the iniferter. The block chain lengths were controlled using iniferter-based radical photopolymerization $[3,25,26]$. The unique feature of iniferter polymerization is that it proceeds in a quasi-living polymerization manner in which “active” and “dormant” propagating chain ends are reversibly equilibrated under UV irradiation. Careful selection of appropriate reaction conditions enables either minimal transfer or termination reactions. In our previous studies, we developed iniferter-based graft-polymerized surfaces [28,29] and block copolymers as surface coatings [30], both of which were designed as biocompatible surfaces. Thus, chain length and block ratio in the surfactant can be easily controlled by iniferter polymerization. The chain lengths of the cationic and thermoresponsive blocks in the adsorbent material were set to approximately 3,000 and $6,000 \mathrm{~g} \cdot \mathrm{mol}^{-1}$, respectively; as a prototype model 
compound (Figure 1). The material was precipitated at approximately $35^{\circ} \mathrm{C}$ due to conversion of the thermoresponsible polymer chains from hydrophilic to hydrophobic (Figure 3). It was considered that chain length of the thermoresponsible chain, balance of block ratio, and branching number were adequate for the success of the strategy employed in this study.

The adsorbent material immediately bioconjugated with pDNA upon mixing with an aqueous medium of pDNA at room temperature to produce polyion complexes approximately $100 \mathrm{~nm}$ in diameter (Figure 2). Even after complexing with pDNA, the material precipitated in a similar manner as in the case in the absence of pDNA (Figure 3). At over approximately $35^{\circ} \mathrm{C}$, the complexes aggregated due to hydrophobic interaction (Figure 3). As illustrated in Figure 6, the produced aggregates were believed to precipitate on the culture substrate; this was confirmed by weight increase measurement using QCM and surface wettability change determined by water contact angle measurement.

In this study, the deposition transfection method was more effective than the reverse transfection and also the conventional transfection methods for enhancing the level of gene expression (Figure 4). The cationic polymers used in the reverse transfection method had a low adsorption ability on the culture substrate. Therefore, a low level of gene expression was obtained even in the deposition transfection method. On the other hand, the expression level was significantly increased when a thermoresponsible cationic polymer was used, indicating the effectiveness of the thermoresponsive polymer chain for adsorption (Figure 4D). The pDNA expression was observed by the following 5 sequential steps: (1) attachment of pDNA onto the cell surface, (2) internalization of pDNA into the cell, (3) endosomal escape of pDNA, (4) transfer of pDNA into the nucleus, and (5) internalization of pDNA into the nucleus. In the deposition transfection method, it was considered that the first step was enhanced due to continuous contact of the cells with pDNA. Interestingly, when the pDNA 
complexes were firmly fixed by drying from the thermoresponsible cationic polymer, the expression level was not as high as in the deposition transfection method (Figure 4C). In order to enhance the internalization of pDNA into the cell, it is considered that pDNA is required to be weakly impregnated in the matrix. Although the intermediate steps occurring from the attachment of pDNA onto the cell surface until the gene expression is unknown, we estimated that the expression occurred in a manner similar to that occurring in the reverse transfection method.

To enhance transfection efficiencies, many research groups have attempted to introduce targeting ligands [31] such as galactose [32], mannose [33], transferrin [34], or antibodies [35] into cationic polymers. On the other hand, a polymeric vector exhibiting variable physicochemical characteristics under different conditions has recently been developed. For example, a temperature-controlled gene expression system, in which a thermosensitive copolymer based on cationized PNIPAM was used, has been synthesized as a thermoreactive vector [36.37]. Increased cellular uptake of the polyplexes, which comprise cationized PNIPAM and DNA, at $37^{\circ} \mathrm{C}$ and their disintegration by the reduction of temperature to $20^{\circ} \mathrm{C}$ were demonstrated. However, the thermoresponsible materials have not been previously applied as the adsorbent materials for pDNA deposition for transfection, as demonstrated in this study.

PNIPAM was applied as the coating material on the culture substrate for cell culture. Because the water solubility of PNIPAM is temperature-dependent as described above, the proliferated cells were collected by changing the temperature alone and without using any proteases [20]. Similarly, the deposited pDNA complexes may be able to detach from the culture substrate upon cooling, and hence, gene-transferred cells can be collected with minimal cellular damage.

In summary, the thermoresponsive cationic material comprised a branched copolymer with cationic and thermoresponsive blocks in order to meet the initial requirements of the adsorbent material to complex with pDNA and the adsorption 
ability on the culture substrate although the developed material was primarily designed as a prototype model. Our understanding of the functionality of the pDNA complexes will be improved if the $M n$ can be established and if the surfactant polymer:pDNA mixing ratio can be optimized. Our future research will be initially directed toward fine-tuning the composition of the adsorbent material. We will then proceed to verify the effectiveness of in vitro gene transfection in vivo.

\section{References}

1) M. Neu, D. Fischer, T. Kissel, Recent advances in rational gene transfer vector design based on poly(ethylene imine) and its derivatives, J. Gene Med. 7 (2005) 992-1009.

2) U. Lungwitz, M. Breunig, T. Blunk, A. Gopferich, Polyethyleneimine-based non-viral gene delivery systems, Eur. J. Pharm. Biopharm. 60 (2005) 247-266.

3) Y. Nakayama, T. Masuda, M. Nagaishi, M. Hayashi, M. Ohira, M. Harada-Shiba, High performance gene delivery polymeric vector: nano-structured cationic star polymers (star vectors), Curr. Drug Deliv. 2 (2005) 53-57.

4) D. Wakabayashi, N. Nishiyama, K. Itaka, K. Miyata, Y. Yamasaki, A. Harada, H. Koyama, Y. Nagasaki, K. Kataoka, Polyiopn complex micells of pDNA with acetal-poly(ethylene glycol)-poly(2-(dimethylamino)ethyl methacrylate) block copolymer as the gene carrier system: physicochemical properties of micelles relevant to gene transfection efficacy, Biomacromolecles 5 (2004) 2128-2136.

5) D.W. Lim, Y.I. Yeom, T.G. Park, Poly(DMAEMA-NVP)-b-PEG-galactose as gene delivery vector for hepatocytes, Bioconjug. Chem. 11 (2000) 688-695.

6) J.Y. Cherng, H. Talsma, D.J. Crommelin, W.E. Hennink, Long term stability of poly((2-dimethylamino)ethyl methacrylate)-based gene delivery systems, 
Pharm. Res, 16 (1999) 1417-1423.

7) S.C. De Smedt, J. Demeester, W.E. Hennink, Cationic polymer based gene delivery systems, Pharm. Res, 17 (2000) 113-126.

8) A. Hirko, F. Tang, J.A. Hughes, Cationic lipid vectors for plasmid DNA delivery, Curr. Med. Chem. 10 (2003) 1185-1193.

9) A.U. Bielinska, A. Yen, H.L. Wu, K.M. Zahos, R. Sun, N.D Weiner, J.R Baker Jr, B.J. Rossler, Application of membrane-based dendrimer/DNA complexes for solid phase transfection in vitro and in vivo, Biomaterials 21 (2000) 877-887.

10) J. Ziauddin, D.M. Sabatini, Microarrays of cells expressing defined cDNAs. 411 (2001) 107-110.

11) H. Erfle, B. Neumann, U. Liebel, P. Rogers, M. Held, T. Walter, J. Ellenberg, R. Pepperkok, Reverse transfection on cell arrays for high content screening microscopy, Nat. Protoc. 2 (2007) 392-399.

12) F. Yamauchi, K. Kato, H. Iwata, Spatially and temporally controlled gene transfer by electroporation into adherent cells on plasmid DNA-loaded electrodes, 32 (2004) e187.

13) A. Okazaki, J. Jo, Y. Tabata, A reverse transfection technology to genetically engineer adult stem cells, Tissue Eng. 13 (2007) in press.

14) T. Otsu, M. Yoshida, T. Tazaki, A model for living radical polymerization, Makromol. Chem. Rapid Commun. 3 (1982) 133-140.

15) T. Otsu, T. Matsunaga, T. Doi, A. Matsumoto, Features of living radical polymerization of vinyl monomers in homogeneous system using N,N-diethyldithiocarbamate derivatives as photoiniferters, Eur. Polym. J. 31 (1995) 67-78.

16) Y. Zhou, H. Huang, Y. Nakayama, Highly effective in vivo gene transfection by blocked star vector, Conf. Proc. IEEE Eng. Med. Biol. Soc. 1 (2005) 
501-503.

17) M. Heskins, J.E. Guillet, Solution properties of poly(N-isopropylacrylamide), J. Macromol. Sci. Chem. A2 (1968) 1441-1455.

18) S. Okajima, Y. Sakai, T. Yamaguchi, Development of a regenerable cell culture system that senses and releases dead cells, Langmuir 21 (2005) 4043-4049.

19) M. Yamato, M. Utsumi, A. Kushida, C. Konno, A. Kikuchi, T. Okano, Thermo-responsive culture dishes allow the intact harvest of multilayered keratinocyte sheets without dispase by reducing temperature, Tissue Eng. 7 (2001) 473-480.

20) M. Nakayama, T. Okano, T. Miyazaki, F. Kohori, K. Sakai, M. Yokoyama, Molecular design of biodegradable polymeric micelles for temperature-responsive drug release, J. Control Release 115 (2006) 46-56.

21) J.X. Zhang, L.Y. Qin, Y. Jin, K.J. Zhu, Thermally responsive polymeric micelles self-assembled by amphiphilic polyphosphazene with poly(N-isopropylacrylamide) and ethyl glycinate as side groups: Polymer synthesis, characterization, and in vitro drug release study. J. Biomed. Mater. Res. A. 76 (2006) 773-780.

22) S. Ohya, H. Sonoda, Y. Nakayama, T. Matsuda, The potential of poly(N-isopropylacrylamide) (PNIPAM)-grafted hyaluronan and PNIPAM-grafted gelatin in the control of post-surgical tissue adhesions, Biometerials 26 (2005) 655-659.

23) S. Ohya, Y. Nakayama, T. Matusda, In vivo evaluation of poly(N-isopropylacrylamide) (PNIPAM)-grafted gelatin as an in situ-formable scaffold, J. Artif. Organs 7 (2004) 181-186.

24) H. Naito, Y. Takewa, T. Mizuno, S. Ohya, Y. Nakayama, E. Tatsumi, S. Kitamura, H. Takano, S. Taniguchi, Y. Taenaka, Three-dimensional cardiac 
tissue engineering using a thermoresponsive artificial extracellular matrix, ASAIO J. 50 (2004) 344-348.

25) Y. Nakayama, M. Miyamura, Y. Hirano, K. Goto, T. Matsuda, Preparation of poly(ethylene glycol)-polystyrene block copolymers using photochemistry of dithiocarbamate as a reduced cell-adhesive coating material, Biomaterials 20 (1999) 963-970.

26) T. Matsuda, J. Nagase, A. Ghoda, Y. Hirano, S. Kidoaki, Y. Nakayama, Phosphorylcholine-endcapped oligomer and block co-oligomer and surface biological reactivity, Biomaterials 24 (2003) 4517-4527.

27) Y. Nakayama, R. Okahashi, R. Iwai, K. Uchida, Heparin bioconjugate with a thermoresponsive cationic branched polymer: A novel aqueous antithrombogenic coating material, Langmuir 23 (2007) 8206-8211.

28) Y. Nakayama, T. Matsuda, Surface macromolecular architectural designs using photo-graft copolymerization based on photochemistry of benzyl N,N-diethyldithiocarbamate. Macromolecules 29 (1996) 8622-8630.

29) W.G. Brodbeck, J. Patel, G. Voskerician, E. Christenson, M.S. Shive, Y. Nakayama, T. Matsuda, N.P. Ziats, J.M. Anderson, Biomaterial adherent macrophage apoptosis is increased by hydrophilic and anionic substrates in vivo, Pro. Natl. Acad. Sci. USA 99 (2002) 10287-10292.

30) Y. Nakayama, T. Matsuda, Surface macromolecular microarchitecture design: Biocompatible surfaces via photo-block-graft copolymerization using N,N-diethyldithiocarbamate, Langmuir 15 (1999) 5560-5566.

31) I. Mizuguchi, Y. Ooe, S. Hoshino, M. Shimura, T. Kasahara, S. Kano, T. Ohta, F. Takaku, Y. Nakayama, Y. Ishizaka, Improved gene expression in resting macrophages using an oligopeptide derived from $\mathrm{Vpr}$ of human immunodeficiency virus type-1. Biochem. Biophys. Res. Commun. 338 (2005) 1499-1506. 
32) Y. Watanabe, X. Liu, I. Shibuya, T. Akaike, Functional evaluation of poly-(N-p-vinylbenzyl-O-beta-D-galactopyranosyl-[1-4]-D-gluconamide)(PV LA) as a liver specific carrier, J. Biomater. Sci. Polym. Ed. 11 (2000) 833-848.

33) Y. Hattori, S. Suzuki, S. Kawakami, F. Yamashita, M. Hashida, The role of dioleoylphosphatidylethanolamine (DOPE) in targeted gene delivery with mannosylated cationic liposomes via intravenous route, J. Control. Release 108 (2005) 484-495.

34) M. Ogris, G. Walker, T. Blessing, R. Kircheis, M. Wolschek, E. Wagner, Tumor-targeted gene therapy: strategies for the preparation of ligand-polyethylene glycol-polyethylenimine/DNA complexes. J. Control. Release 91 (2003) 173-181.

35) C.R. Dass, P.F. Choong, Selective gene delivery for cancer therapy using cationic liposomes: in vivo proof of applicability, J. Comtrol. Release 113 (2006) 155-163.

36) M.D. Lavigne, S.S. Pennadam, J. Ellis, L.L. Yates, G. Alexander, D.C. Gorecki, Enhanced gene expression through temperature profile-induced variations in molecular architecture of thermoresponsive polymer vectors, J. Gene Med. 9 (2007) 44-54.

37) M. Yokoyama, Gene delivery using temperature-responsive polymeric carriers, Drug Discov. Today 7 (2002) 426-432. 


\section{Figure Captions}

Figure 1. Chemical structure of the cationic thermoresponsive copolymer (PDMAPAAm-PNIPAM 4-branched block copolymer) as an adsorbent material.

Figure 2. Particle sizes of the cationic thermoresponsive copolymer (PDMAPAAm-PNIPAM 4-branched block copolymer) and its polyplex with pDNA at $25^{\circ} \mathrm{C}$ and $37^{\circ} \mathrm{C}$.

Figure 3. Thermoresponsive changes in the transmittance of the cationic thermoresponsive copolymer (PDMAPAAm-PNIPAM 4-branched block copolymer) and its polyplex with pDNA. Polymer concentration : 10 $\mathrm{mg} \cdot \mathrm{mL}^{-1}$, pDNA concentration: $5 \mathrm{mg} \cdot \mathrm{mL}^{-1}$. Heating rate: $0.5^{\circ} \mathrm{C} \cdot \mathrm{min}^{-1}$.

Figure 4. Transfection efficiency using the cationic polymer (PDMAPAAm 4-branched polymer) (A) and the cationic thermoresponsive copolymer (PDMAPAAm-PNIPAM 4-branched block copolymer) (D) in deposition transfection, and in the conventional transfection (B) and reverse transfection methods (C).

Figure 5. Cytotoxicity of $(\bullet)$ polyplexes prepared by mixing DNA (pGL3-control) and the cationic thermoresponsive copolymer (PDMAPAAm-PNIPAM 4-branched block copolymer) in different the charge ratio and $(\circ)$ polyplexes from the DNA and PEI (Exgen500). Cell viability was determined by the WST assay.

Figure 6. Illustration of handling in the deposition transfection method. 


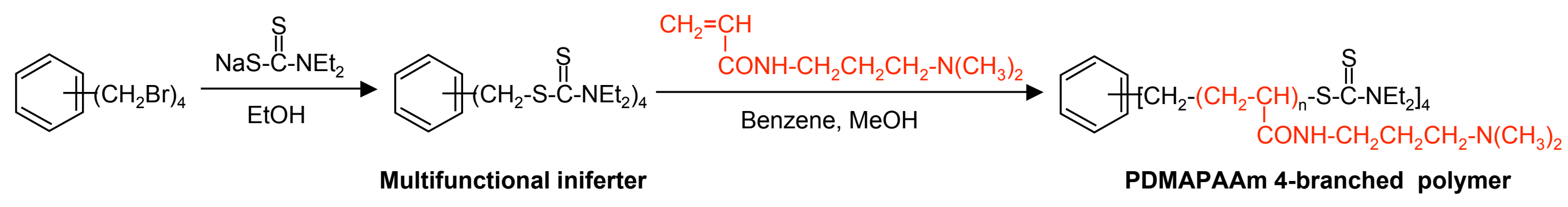

\section{PDMAPAAm 4-branched polymer}
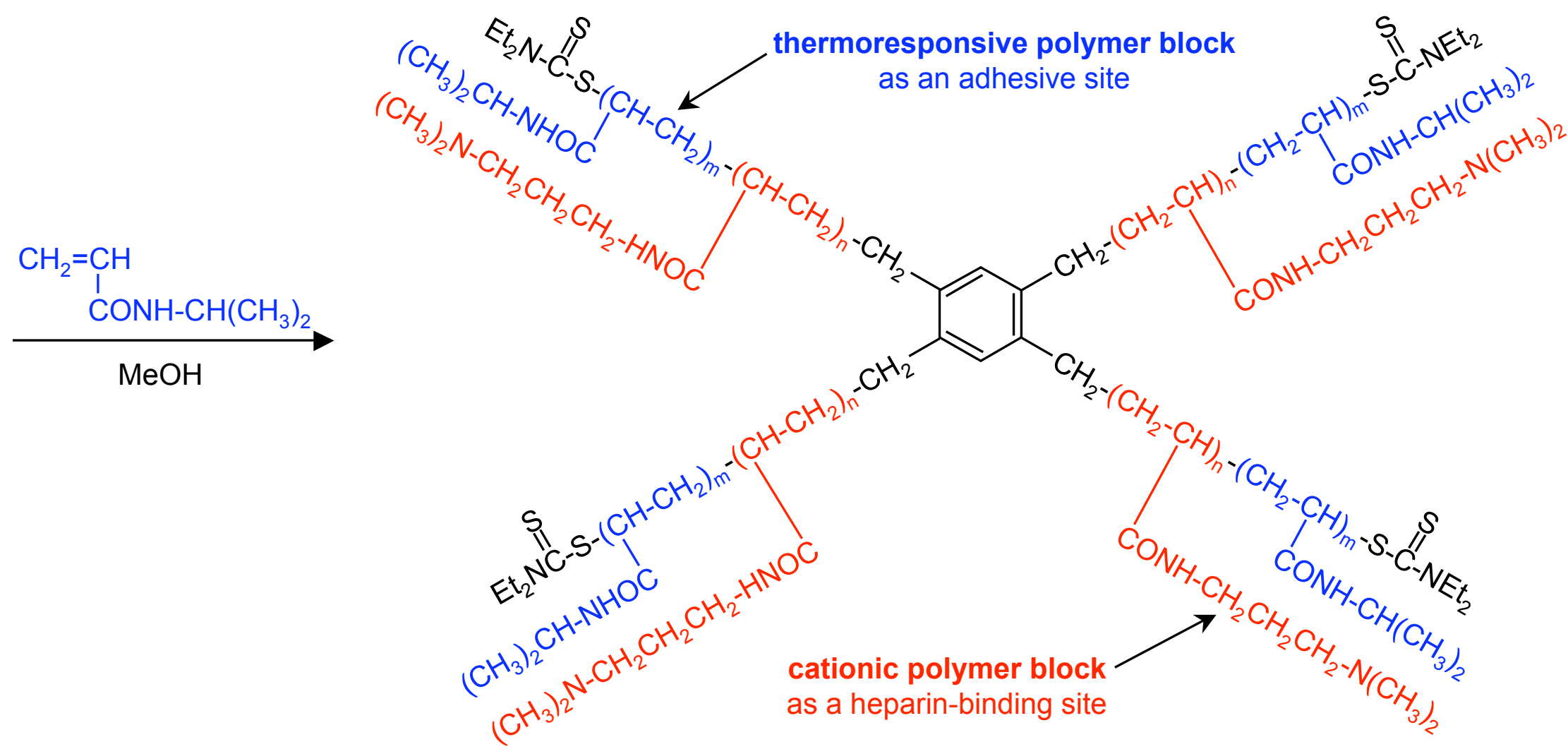

PDMAPAAm-PNIPAM 4-branched block copolymer 


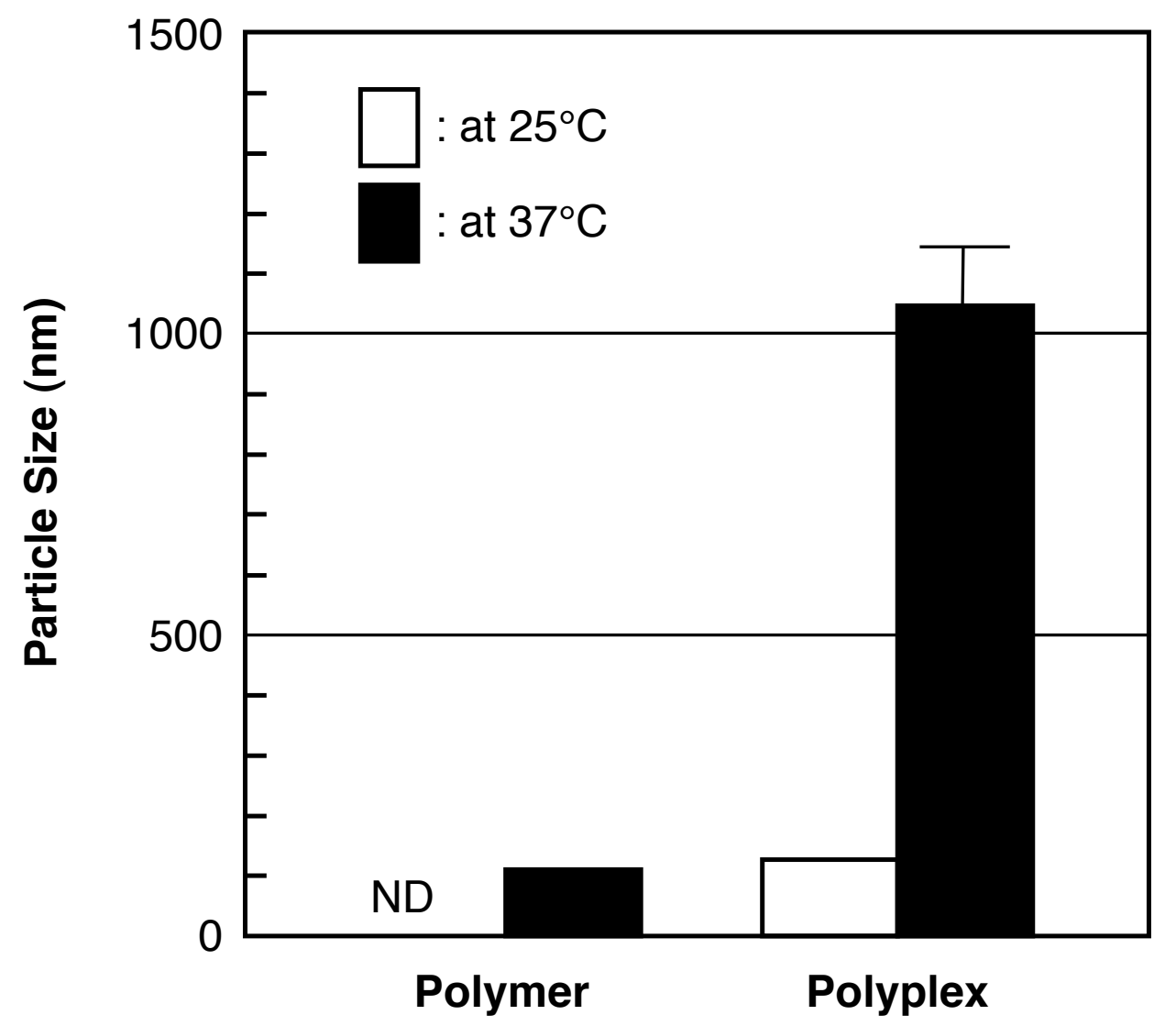

Figure 2 


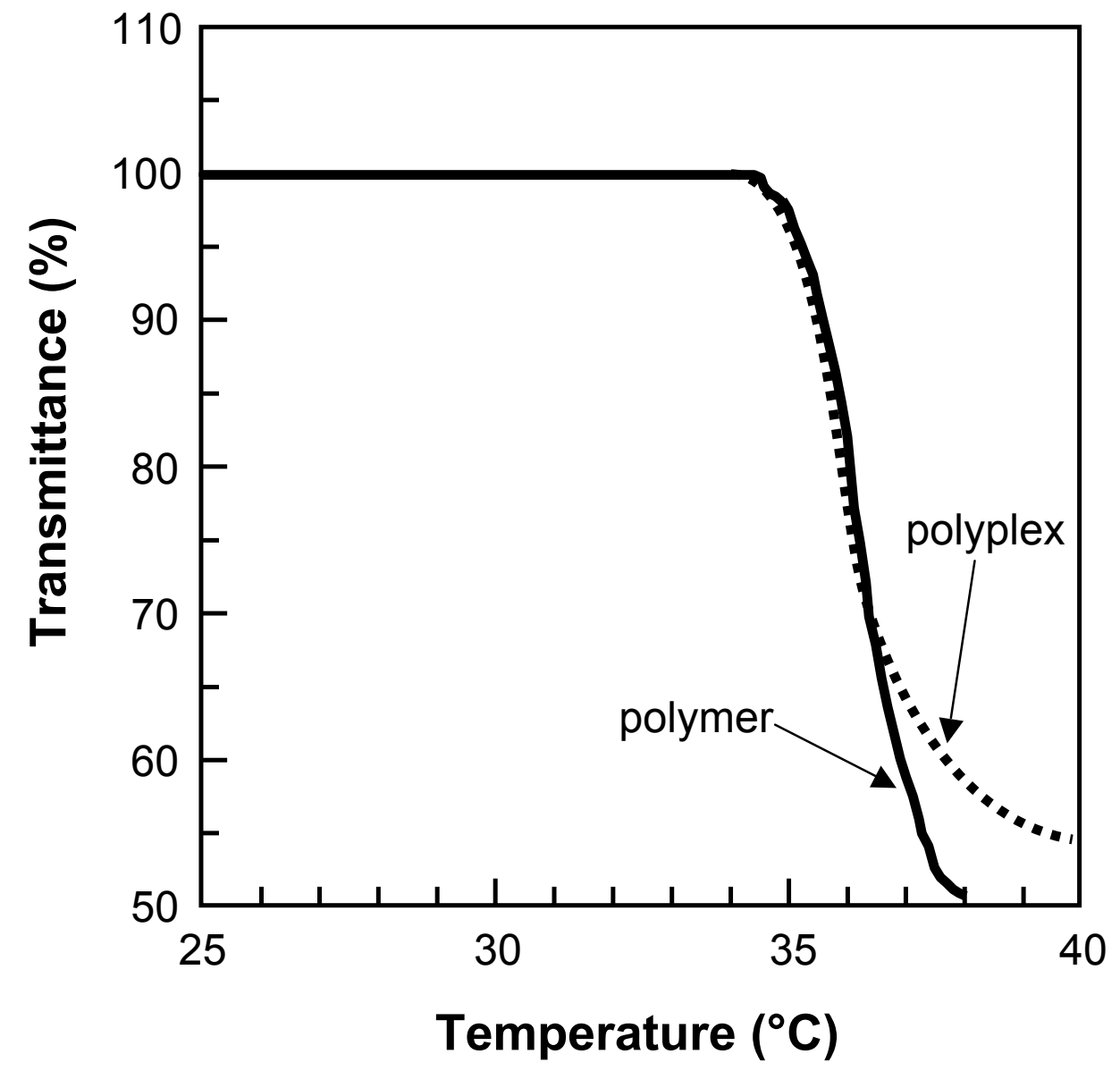

Figure 3 


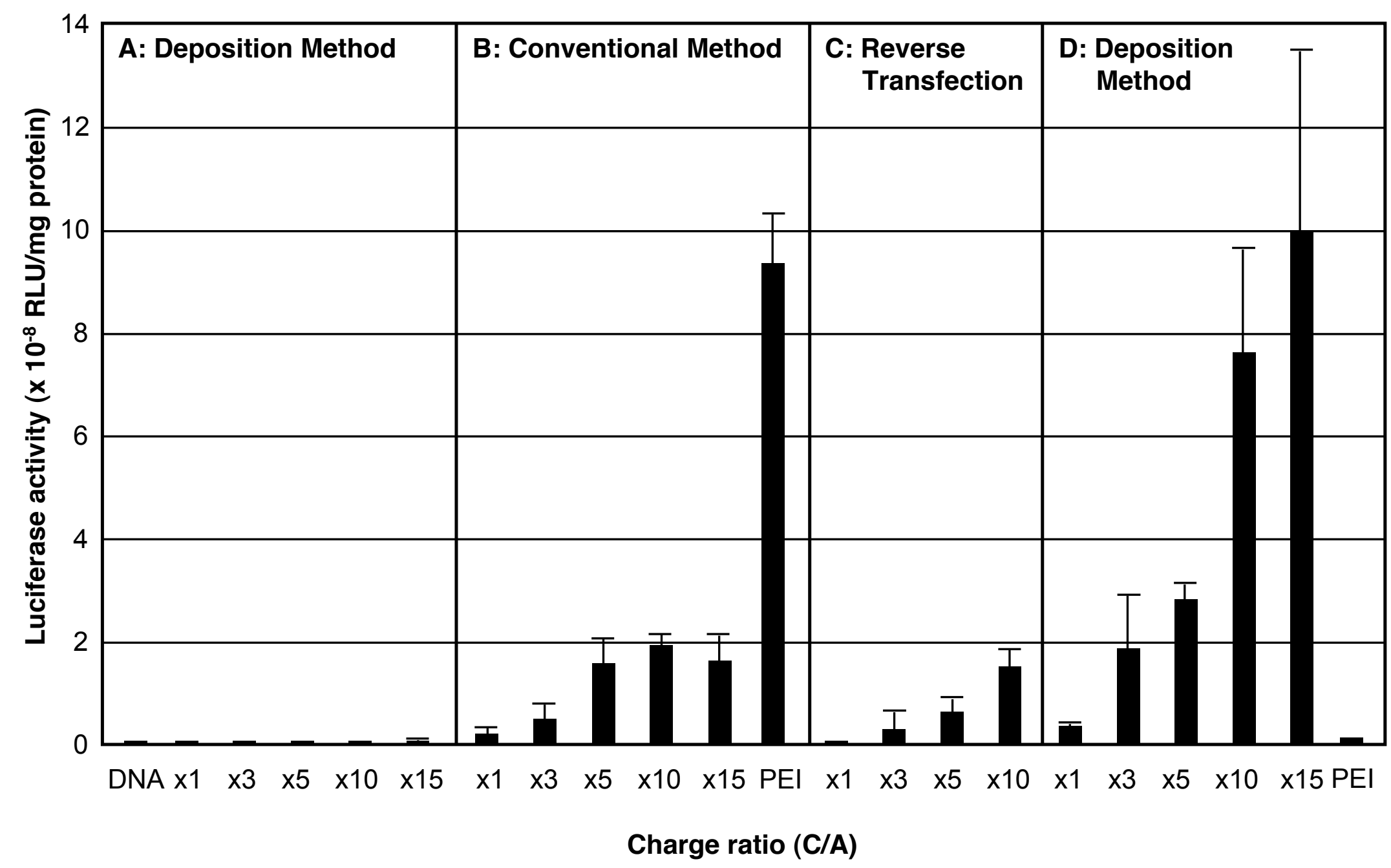

Figure 4 


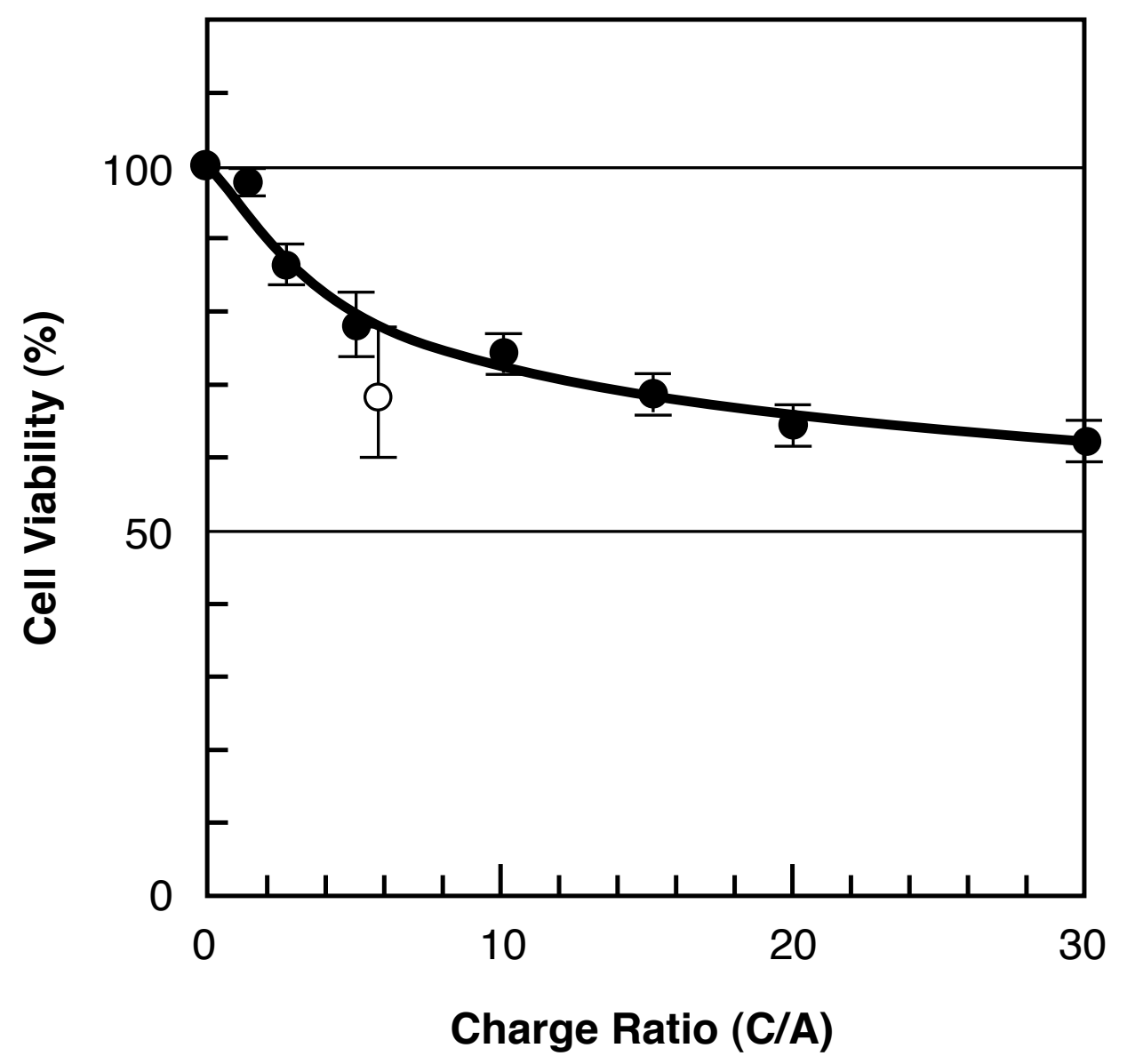

Figure 5 

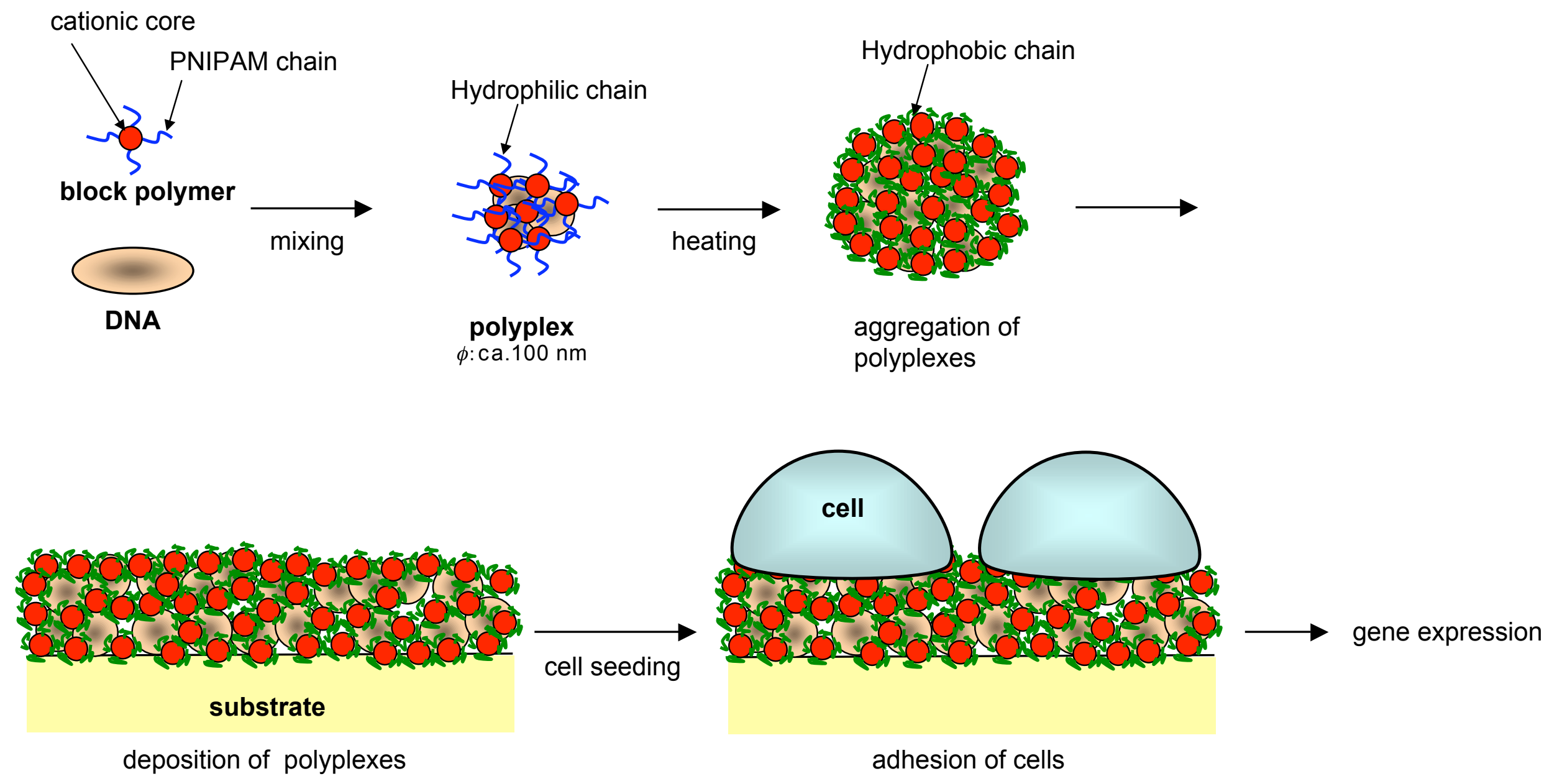